\title{
Manuscript
}

\section{Albuminuria Regression and All-cause Mortality among Insulin-treated Patients with Type 2 diabetes: Analysis of a Large UK Primary Care Cohort}

Running Head: Albuminuria Regression and Total Mortality among Patients with Type 2 diabetes

\author{
U Anyanwagu' ${ }^{1}$ MD, PhD; R Donnelly ${ }^{1}$ MD, PhD; I Idris ${ }^{1,2}$ MD, DM. \\ ${ }^{1}$ Division of Graduate Entry Medicine, School of Medicine, University of Nottingham, UK \\ ${ }^{2}$ National Institute of Health Research, Nottingham Biomedical Research Centre
}

Key words: Albuminuria, mortality, insulin, Type 2 diabetes

Word count

Abstract: 305

Main text: 2800

Tables: 3

Figures: 3

\section{Correspondence:}

Dr Iskandar Idris

Division of Medical Sciences \& Graduate Entry Medicine,

School of Medicine, University of Nottingham,

Royal Derby Hospital Centre, Uttoxeter Road,

Derby DE22 3DT, UK

Email: Iskandar.idris@nottingham.ac.uk

Tel: 01332724668 
Funding: This work was supported by the Medical Research Council [grant numbers MR/K00414X/1 and MR/P021220/1]; and Arthritis Research UK [grant number $19891]$.

Conflict of Interest: None declared for all authors relating to the content of this manuscript. 


\begin{abstract}

\section{Background}

Overt albuminuria (urinary albumin-creatinine ratio (ACR) $>300 \mathrm{mg} / \mathrm{g}$ ) is an established risk factor for progression of nephropathy and total mortality. However, whether, a reduction in ACR translates into a reduction in mortality and/or cardiovascular events among insulintreated patients with Type 2 diabetes (T2D) in routine practice is currently not known.
\end{abstract}

\title{
Methods
}

We obtained data on a large cohort of insulin users with T2D and nephropathy (baseline ACR $\geq 300 \mathrm{mg} / \mathrm{g}$ ) from UK general practices between 2007 and 2014. Their corresponding ACR values after one year of follow up were thereafter categorised into: (1) <300mg/g (i.e. albuminuria regression) or (2) $>300 \mathrm{mg} / \mathrm{g}$ (i.e. non-regression of albuminuria), and the cohort was followed up for 5 years for all-cause mortality and cardiovascular events. Cox proportional hazard models were fitted to estimate the risk of all-cause death.

\section{Results}

A total of 11,074 patients with insulin-treated T2D met the inclusion criteria. Their mean age was 62.3(13.6) years; mean HbA1c: 8.7(1.8) \%; and 53\% were male. 682 deaths occurred after a follow-up period of 43,393 person-years with a mortality rate of 16 per 1000 personyears. 5-year survival was markedly reduced in the group whose proteinuria persisted or progressed (91 vs 95\%; log-rank p-value <0.001). Compared to patients whose ACR levels remained above $300 \mathrm{mg} / \mathrm{g}$, all-cause mortality and cardiovascular events were $31 \%$ and $27 \%$ lower in those whose albuminuria regressed to $<300 \mathrm{mg} / \mathrm{g}$ (aHR: $0.69 ; 95 \%$ CI: 0.52 to 0.91 ; $\mathrm{p}=0.008$ and aHR: 0.73 ; 95\%CI: 0.54 to $0.98 ; \mathrm{p}=0.041$ ) respectively.

\section{Conclusion}

In patients with insulin-treated T2D and nephropathy in routine practice, a regression in albuminuria (e.g. via better BP or glycaemic control) is associated with a significant reduction in all-cause mortality. Thus, albuminuria is not simply a risk marker of renal and cardiovascular disease, but also an independent target for therapy. Albuminuria reduction should be viewed as a goal for renal and cardiovascular protection. 


\section{Research in context:}

What is already known about this subject?

- Albuminuria is a strong predictor of adverse renal and cardiovascular outcomes in patients with Type 2 Diabetes (T2D), hypertension and in the general population.

- Several therapeutic strategies are available to reduce ACR, namely via interruption of the Renin-Angiotensin system (RAS) with either angiotensin-converting enzyme (ACE) inhibitors or Angiotensin II receptor blocker; strategies to achieve tight glucose control; and the use of Sodium Glucose co-transporter (SGLT)-2 inhibitor.

- Previous sub-analysis of studies have shown that the reduction in albuminuria achieved in the first months of RAS blockade predicts long-term renal and cardiovascular risk reduction

What is the key question?

- Among patients with Insulin treated Type 2 diabetes with overt proteinuria $(A C R>300 \mathrm{~g} / \mathrm{g}$ ), undergoing routine treatment in primary care, does regression of proteinuria confer an associated reduction in cardiovascular events and total mortality compared with patients whose proteinuria did not regress?

What are the new findings?

- Among this cohort of patients with Insulin treated Type 2 diabetes, increased albuminuria is an independent marker for subsequent cardiovascular events and total mortality in real world setting.

- Regression of albuminuria as a result of multifactorial intervention in routine clinical care was associated with a further significant reduction in cardiovascular events and total mortality events compared with patients whose albuminuria did no regress.

- The beneficial impact of albuminuria regression appears to be stronger for total mortality than for cardiovascular endpoints, regression of albuminuria is not associated with a significant reduction in non-fatal myocardial infarction but, was associated with a significant reduction in stroke event, compared with the cohort whose albuminuria level either increased or did not regress.

How might this impact on clinical practice in the foreseeable future?

- Thus, levels of albuminuria should be considered not only as an important risk marker, but also an important therapeutic target for cardiovascular and mortality prevention in patients with $\mathrm{T} 2 \mathrm{D}$, and should be a key consideration when determining drug choice irrespective of blood pressure and glucose levels. 


\section{Introduction}

Albuminuria is a strong predictor of adverse renal and cardiovascular outcomes in patients with Type 2 Diabetes (T2D), hypertension and in the general population. [1-4] Albuminuria is typically assessed by measuring urinary albumin to creatinine ratio (ACR). ACR levels between $30 \mathrm{mg} / \mathrm{g}$ to $300 \mathrm{mg} / \mathrm{g}$ represent moderately increased levels of albuminuria, known as microalbuminuria, while levels of more than $300 \mathrm{mg} / \mathrm{g}$ are associated with overt proteinuria. Several therapeutic strategies are available to reduce ACR, namely via interruption of the Renin-Angiotensin system (RAS) with either angiotensin-converting enzyme (ACE) inhibitors or Angiotensin II receptor blocker [5,6]; strict BP control; strategies to achieve tight glucose control [7]; and more recently, the Sodium Glucose co-transporter (SGLT)-2 inhibitor [8,9]. While these strategies are also associated with improvement in renal and cardiovascular outcomes, the precise impact of ACR reduction, independent of conventional cardiovascular risk parameters, in mediating the beneficial effect of cardio-renal outcome remains unclear.

For many patients with T2D, insulin treatment will be required to control hyperglycaemia and to reduce the risk of long-term vascular complications in patients with T2D. [10-12]. However, insulin therapy is known to induce $\sim 4-9 \mathrm{~kg}$ weight gain in the first year of treatment. [13] This is relevant within the context of diabetic nephropathy since obesity is also a significant risk factor for the appearance of proteinuria and ESRD. [14] Furthermore, recent evidence from randomized controlled trial, epidemiological and observational studies have implicated insulin therapy in patients with T2D with increased CV risk and mortality of [15-18], possibly due to weight gain, recurrent hypoglycaemia, potential adverse effects of iatrogenic hyperinsulinemia as well as a surrogate marker of increased diabetes duration 
[19.20]. Thus, a cohort of insulin-treated patients with T2D, represents a complex heterogeneous challenging group of patients, many of whom have significant comorbidities and high CV disease risk.

Although previous studies have shown that the reduction in albuminuria achieved in the first months of RAS blockade predicts long-term renal and cardiovascular risk reduction [21, 22] implying a causal association between albuminuria with cardio-renal risks [23], no previous study has been performed to investigate the independent effects of reduction in albuminuria on cardiovascular events and total mortality among insulin-treated patients with T2D in realworld primary care, given that insulin initiators usually have poor glycaemic control, longer disease duration or may be more advanced in age, and a reduction in ACR amongst them could be associated with marked reduction in these events.

\section{Methods}

\section{Study Design}

Using a large UK Primary Care database - The Health Improvement Network (THIN) Database - we conducted a historic cohort study among patients with T2D currently on insulin. THIN is a large UK electronic Primary Care database with clinical details of over 12.4 million patients, of which about 3.61 million are active. Data are imputed with the longitudinal records from about 587 General Practices which are obtained and updated regularly.

The routine clinical information of these patients are constantly and systematically entered into this database by trained doctors and specialist nurses. Data of specialist or Primary Care consultations, diagnoses, laboratory results, prescriptions, referrals, hospital admissions, immunisations, to important clinical measures such as body weight, height and body mass index (BMI) as well as information on the patients' demography (e.g. age, and gender) 
lifestyle characteristics (e.g. alcohol use and smoking), socio-economic status (measured by the Townsend deprivation scores) are also included.

THIN database has been validated by various studies and shown to be demographically representative of the UK population in terms of indices of diseases and patients' demography [24]. Our research group has extensively used the THIN database in evaluating diabetesrelated outcomes in routine clinical practice $[25,26]$.

\section{Study Participants}

We obtained routine clinical data on 11,074 patients with a diagnosis of T2D who met our inclusion criteria. These were adults (aged 18 years and above) who were on insulin therapy between December 2006 and May 2014, irrespective of the use of other glucose-lowering therapies (GLTs). These patients must have recorded values of ACR at baseline and one year after insulin initiation. Only those with those with nephropathy (ACR levels above $300 \mathrm{mg} / \mathrm{g}$ ) were included. Urinary ACR in the dataset was measured from a single voided urine sample by a central laboratory, with the lowest detectable and reportable level of $1.0 \mathrm{mg} / \mathrm{g}$.

Excluded from the study were those with missing baseline data of ACR and those with medical codes for type 1 or gestational diabetes, or other forms of diabetes, alongside those with no continuous regular prescriptions for insulin in their records for more than 6 months.

\section{Follow-up and Endpoints}

The selected study participants with nephropathy at insulin initiation (baseline date) were followed up from this date for one year. Post-one year ACR levels were estimated and patients were grouped into two: those with ACR levels now $<300 \mathrm{mg} / \mathrm{g}$ vs those with ACR $\geq$ $300 \mathrm{mg} / \mathrm{g}$. Patients were then followed up from this point until occurrence of the primary or secondary endpoint, or loss to follow-up, or discontinuation of insulin therapy, or at the end of the 5-year follow-up period.

The primary endpoints were all-cause mortality and cardiovascular events (a composite of non-fatal myocardial infarction and stroke). 
The secondary endpoint was a 3-composite of Major Adverse Cardiovascular Events (MACE) which includes all-cause mortality or non-fatal myocardial infarction or stroke; and the component parts of non-fatal myocardial infarction and stroke.

All these outcomes were identified using their appropriate Read Codes in the database.

\section{Baseline and endpoint characteristics}

To be able to adjust for the effect of possible a priori confounders on the study endpoints, data were also obtained on important baseline clinical covariates Among these were demographic variables as age, gender, socioeconomic status, alcohol and smoking status; important clinical measures such as body weight, height, SBP and DBP; biochemical parameters, e.g. baseline $\mathrm{HbA1c}$, lipid-profile, use of other medications including other glucose-lowering therapies (GLTs); as well as comorbidity status, duration of diabetes treatment, and duration of insulin use. We computed the change in mean arterial pressure (MAP) and HbA1c after one year of insulin initiation; and alongside baseline covariates with significant differences between the two groups, these were adjusted for in the final Cox model.

\section{Statistical Analysis}

Multiple imputations using the chained equation (MICE) model were used to input missing data for some important baseline clinical covariates as weight, HbA1c, eGFR, weight, SBP and DBP which were found to be completely missing at random (MAR).

Baseline data were summarised for the two groups using mean with standard deviations for continuous variables; and absolute numbers with proportions (\%) for categorical variables. The differences in baseline characteristics between the two groups were estimated using Pearson's chi-squared test for categorical, and Student t-test for continuous variables.

Kaplan-Meier survival curves were estimated separately for both treatment groups. From these survival functions, we calculated the absolute reduction in the probability of an event occurring within the 5-year follow-up period.

Using the Cox regression model, the marginal Hazard Ratios (HRs) were estimated in order to quantify the adjusted hazard (aHR) of an event occurring in the "ACR below $300 \mathrm{mg} / \mathrm{g}$ " 
group compared with the "ACR 300mg/g and above" group. We tested for violations of the proportional hazard assumption of the Cox regression model, by adding an interaction term of the predictor; and by log-minus-log survival curves; and finally confirmed the proportional hazards assumptions were through Schoenfeld residuals test.

Point estimates were computed with 95\% confidence intervals (CI) at the conventional statistical significance level of 0.05. Stata Software version 15 was used for all the analyses.

\section{Ethical Approval:}

This was obtained from the South-East Research Ethics Committee, UK

\section{Results}

\section{Patient Characteristics.}

A total of 11,074 new insulin initiators met our inclusion criteria. Of this, 1552 (14\%) had reduction in albuminuria, as against 9522 (86\%) who had persistent or progressive albuminuria after one year of intensive glucose control with insulin.

Their overall mean age was $62.3 \pm 14$ years, mean baseline HbA1c and eGFR were $8.7 \pm 1.8 \%$ and $59.9 \pm 21.2 \mathrm{mls} / \mathrm{min} / 1.73 \mathrm{~m}^{2}$ respectively. Table 1 is a summary of the baseline characteristics of the study participants, stratified by the two treatment groups.

From Table 1, it can be seen that at baseline, those with their post-one year ACR less than $300 \mathrm{mg} / \mathrm{g}$ were younger $(\mathrm{p}<0.001)$; less obese and overweight $(\mathrm{p}=0.002)$; had less comorbidities $(\mathrm{p}<0.05)$; shorter duration of diabetes before insulin initiation $(\mathrm{p}=0.004)$; higher eGFR ( $\mathrm{p}<0.001)$; and lower systolic and diastolic BP $(\mathrm{p}<0.05)$. Conversely, the use of other GLTs, baseline HbAlc and lipid profile were similar in both groups (all $\mathrm{p} \geq 0.05$ ).

\section{Primary Endpoint}


i. All-Cause Mortality: Survival analyses at 5 years were $91 \%$ vs $95 \%$ for patients with ACR above 300mg/g (group 1) vs those with ACR below 300mg/g (group 2); log-rank test pvalue $<0.001$ (Figure 1). Overall, there were 682 deaths with a crude incidence rate of 15.7 per 1000 person-years (95\%CI: 14.6 to 17.0) within a total follow-up period of 43,393 person-time. There were 621 vs 61 deaths in group 1 vs 2 .with an unadjusted mortality rates of 16.7 vs 9.7 per 1000 person-years (Table 2).

In the unadjusted model, the risk of all-cause mortality was $43 \%$ less (aHR: $0.57,95 \% \mathrm{CI}$ : 0.44 to $0.75, \mathrm{p}<0.001$ ) in group 2 compared to group 1 . Following adjustment for change in HbA1c and Mean arterial pressure (MAP) and other significantly different baseline covariates in Table 1 , this reduced to $31 \%$ (aHR: $0.69,95 \%$ CI: 0.52 to $0.91, p=0.008$ ) (Table 2)

ii. Cardiovascular (CV) Events: After a total follow-up period of 38,274 person-time, the 5year survival probabilities for CV events were 94\% vs 96\% in group 1 vs group 2 (log-rank test $\mathrm{p}$-value $=0.007)$; with an overall event rate of 12.6 per 1000 person-years $(95 \% \mathrm{CI}: 11.7$ to 13.9 ) - 13.4 vs 5.6 per 1000person-years in group 1 vs 2 respectively (Table 2). The risk of $\mathrm{CV}$ events was $27 \%$ less in group 1 (aHR: $0.73,95 \% \mathrm{CI} 0.54$ to $0.98, \mathrm{p}=0.041$ ) compared to group 2, even after adjustment.

\section{Secondary Endpoint}

i. Composite MACE: The probability of survival for composite MACE fell from $98 \%$ in both groups at year 1 to $84 \%$ vs $90 \%$ in group 1 and 2 respectively at 5 years (log-rank pvalue $<0.001)$ Figure $3 \mathrm{~A}$. Overall, there were 1,173 composite MACE $(1,062$ in group 1 vs 111 in group 2) with a crude event rate of 30.7 per 1000 person-years (95\% CI: 30.0 to 32.5). See Table 3. The risk of MACE in the adjusted Cox model was $27 \%$ less in group 2 compared to group 1 (aHR: $0.737,95 \%$ CI: 0.59 to $0.89, \mathrm{p}=0.002$ ).

ii. Non-fatal Myocardial Infarction (MI) and Non-fatal Stroke: For non-fatal MI, there were no differences in survival between both groups (log-rank test $p$-value $=0.086$ ), unlike in non-fatal stroke in which the survival probabilities fell from $99 \%$ at the first year to $94 \%$ vs $96 \%$ at 5 year $(\log$-rank test $\mathrm{p}$-value $=0.03)$. These are shown in the Kaplan-Meier curves in 
Figures 3B and C. In both groups, there was a total of 69 and 419 events of non-fatal MI and stroke respectively (Event rates $=1.6$ vs 10.6 per 1000 person-years). The events between the two treatment groups are summarised in Table 3.

There was no statistically significant difference in the risk of non-fatal MI between the treatment groups $(\mathrm{aHR}=0.66,95 \% \mathrm{CI}: 0.26$ to $1.70, \mathrm{p}=0.387)$ while for stroke, patients whose proteinuria regressed to $<300 \mathrm{mg} / \mathrm{g}$ (group 2) had a $30 \%$ reduction $(\mathrm{aHR}=0.72$; 95\%CI: 0.52 to $0.97 ; \mathrm{p}=0.032$ ) in risk compared to those with persistent or progressive proteinuria (group 2). 


\section{Discussion}

The present study showed that albuminuria is an independent marker for subsequent cardiovascular events and total mortality in insulin-treated patients with T2D. Regression of albuminuria as a result of multifactorial intervention in routine clinical care was associated with a further significant reduction in cardiovascular events and total mortality events. This association appears to be marginally stronger for total mortality than for cardiovascular endpoints. In addition, we found that regression of albuminuria was associated with reduction in non-fatal myocardial infarction (though not statistically significant) but, interestingly, was associated with a significant reduction in stroke event, compared with the cohort whose albuminuria level either increased or did not regress. Thus, levels of albuminuria should be considered not only as an important risk marker, but also an important therapeutic target for cardiovascular and mortality prevention in patients with $\mathrm{T} 2 \mathrm{D}$, and should be a key consideration when determining drug choice irrespective of blood pressure and glucose levels.

Albuminuria has long been recognised to be a risk marker for the severity of kidney disease. Although early opinion suggests that albuminuria is simply a surrogate marker of renal injury, evidence in the last 12 years however, have shown the cause-effect relationship between albuminuria and progressive kidney damage [21-23]. Our present study, obtained in a large retrospective cohort of patients with insulin-treated T2D undergoing routine care in UK general practices, shows that this phenomenon may also apply to cardiovascular event and total mortality. This is akin to the impact of blood pressure and serum cholesterol, where therapeutic strategies have been designed and with the aim to lower blood pressure and serum cholesterol respectively. Indeed, there are recognised therapeutic strategies that can 
reduce the degree of albuminuria - namely antihypertensive agents such as ACE inhibitor and Angiotensin-2 receptor blocker [5,6], tight glucose control [7], SGLT2 inhibitors [8,9 ], and low protein diet [27]. Since RAS blockade and SGLT2 inhibitor also lower blood pressure, it remained speculative whether the changes in albuminuria per se affect the cardiovascular/mortality endpoints independently of blood pressure. However, individual variations to RAS blockade is well described - i.e. patients can have a systolic blood pressure reduction without a simultaneous reduction in albuminuria or vice versa [28]. This discordance in response to RAS blockade has been reported in clinical trial [29] as well as in population treated in routine clinical practice [30], and that the beneficial impact of albuminuria reduction was reported to be independent of blood pressure reduction. A particularly important finding from this present study was the fact that the cardiovascular and total mortality reduction was not observed in the cohort whose albuminuria did not regress, following adjustment for conventional cardiovascular factors. The current study for the first time shows on a large scale, in a real-world practice that the degree of albuminuria reduction is directly related to the subsequent cardiovascular and mortality protection in a high risk group of patients with T2D.

In the absence of a prospectively-designed clinical study, with appropriate treatment arms and robust endpoints, the mechanism linking albuminuria and excess mortality remains speculative. The Steno hypothesis suggested that urinary protein excretion reflects generalised vascular endothelial dysfunction [31] - e.g. increased circulating von Willebrand Factor (vWF) antigen released [32] and nitric oxide inhibition [33] in response to endothelial cell damage. In addition to vWF, soluble vascular cell adhesion molecule, fibrinogen, high platelet adhesiveness, erythrocytes aggregation and tissue plasminogen activator have been found to correlate with urinary albumin excretion [34], especially in patients with diabetes, 
indicating increased thrombosis risk. Proteinuria is also linked with insulin resistance, a recognised marker and mediator of atherogenesis [35]. More recently, a key mechanism that contributes to the link between albuminuria and adverse cardiovascular outcome relates to the loss of the glycocalyx--a polysaccharide gel that lines the luminal endothelial surface and that normally acts as a barrier against albumin filtration [36]. Degradation of the glycocalyx in response to endothelial activation can lead to albuminuria and subsequent vascular inflammation, thus providing a pathophysiological framework for the clinical association of albuminuria with renal and cardiovascular disease progression.

The main strength of our study derives from the inclusion of a large cohort of patients with T2D receiving insulin therapy in a real-world population which is largely representative of the UK population. This implies that our findings will be generalizable to various population that share similar demographics. The large cohort of patients studied here provides adequate statistical power which also enabled the component endpoints to be studied. It also contains information on other time-varying covariates to adjust for possible confounders. We adjusted for a large set of factors that could have differed at the baseline. Nevertheless, some residual confounding in our study could persists. For example, our classification of albuminuria was largely based on a single measurement, in contrast to current recommendation, in which at least two measurements are required. In addition, as is the case in all studies of CV or ESRD risk associated with eGFR and albuminuria, the effect of competing hazards may bias estimates of risk. This is because elevated ACR and low eGFR are also risk factors for nonrenal diseases, associated differential mortality in high-risk individuals may confound hazard ratio estimates for $\mathrm{CV}$ events. Lastly, changes after baseline in medications were not evaluated in this analysis and therefore cannot account for any differences that might influence the association between ACR and outcomes. 
In summary, the findings of this study extend the cause-effect relationship between albuminuria and cardiovascular risks and that suppressing albuminuria should be an important target of therapy to achieve optimal cardiovascular protection in high risk individuals with T2D. While further prospective interventional studies are required to clarify the cause effect relationship, we would suggest that cardiovascular risk reduction guidelines on patients with T2D should not only view albuminuria as an important risk factor/marker, but should also define albuminuria regression as a target for therapy, similar to lipids, blood pressure and glucose targets.

\section{Reference}

1. Ninomiya T, Perkovic V, de Galan BE et al. Albuminuria and kidney function independently predict cardiovascular and renal outcomes in diabetes. J Am Soc Nephrol 2009; 20: 1813-1821.

2. Wachtell $\mathrm{K}$, Ibsen $\mathrm{H}$, Olsen $\mathrm{MH}$ et al. Albuminuria and cardiovascular risk in hypertensive patients with left ventricular hypertrophy: the LIFE study. Ann Intern Med 2003; 139: 901-906.

3. Hillege HL, Fidler V, Diercks GF et al. Urinary albumin excretion predicts cardiovascular and noncardiovascular mortality in general population. Circulation 2002; 106: 1777-1782.

4. Hemmelgarn BR, Manns BJ, Lloyd A, James MT, Klarenbach S, Quinn RR, Wiebe N, Tonelli M: Relation between kidney function, proteinuria, and adverse outcomes. JAMA 2010; 303: 423-429 
5. Lewis EJ, Hunsicker LG, Bain RP, Rohde RD The effect of angiotensin-convertingenzyme inhibition on diabetic nephropathy. N Engl J Med 1993; 329:1456-1462

6. Lewis EJ, Hunsicker LG, Clarke WR, et al. et al: Renoprotective effect of the angiotensin-receptor antagonist irbesartan in patients with nephropathy due to type 2 diabetes. $N$ Engl J Med 2001; 345:851-860

7. The ADVANCE Collaborative Group. Intensive blood glucose control and vascular outcomes in patients with type 2 diabetes. $N$ Engl J Med 2008;358:2560-2572

8. Zinman B, Wanner C, Lachin JM et al Empagliflozin, cardiovascular outcomes, and mortality in type 2 diabetes. $N$ Engl J Med 2015; 373:2117-2128

9. Cherney DZI, Zinman B, Inzucchi SE, Koitka-Weber A, Mattheus M, von Eynatten M, Wanner C. Effects of empagliflozin on the urinary albumin-to-creatinine ratio in patients with type 2 diabetes and established cardiovascular disease: an exploratory analysis from the EMPA-REG OUTCOME randomised, placebo-controlled trial. Lancet Diabetes Endocrinol. 2017; 5:610-621.

10. Holman RR, Paul SK, Bethel MA, Matthews DR, Neil HA. 10-year follow-up of intensive glucose control in type 2 diabetes. N Engl J Med 2008; 359: 1577-89.

11. Ray KK, Seshasai SRK, Wijesuriya S, et al. Effect of intensive control of glucose oncardiovascular outcomes and death in patients with diabetes mellitus: a metaanalysis of randomised controlled trials. The Lancet 2009; 373: 1765-72.

12. Inzucchi SE, Bergenstal RM, Buse JB, et al. Management of Hyperglycemia in Type 2 Diabetes, 2015: A Patient-Centered Approach: Update to a Position Statement of the American Diabetes Association and the European Association for the Study of Diabetes. Diabetes Care 2015; 38: 140-9.

13. Russell-Jones D, Khan R. Insulin-associated weight gain in diabetes - causes, effects and coping strategies. Diabetes, Obesity and Metabolism 2007; 9: 799-812.

14. Praga M, Morales E. Obesity, proteinuria and progression of renal failure. Curr Opin Nephrol Hypertens. 2006; 15:481-6. 
15. The Action to Control Cardiovascular risk in diabetes study Group. Effects of Intensive Glucose lowering in type 2 Diabetes. New England J Med. 2008; 358:2545

16. Van Avendonk MWJ, Rutten GEH. Insulin therapy in type 2 diabetes: what is the evidence? Diabetes, Obesity and Metabolism 11(5): 415-432.

17. Currie CJ, Poole CD, Evans M, Peters JR, Morgan CL. Mortality and other important diabetes-related outcomes with insulin vs other antihyperglycemic therapies in type 2 diabetes. J Clin Endocrinol Metab 2013; 98: 668-77.

18. Roumie CL, Greevy RA, Grijalva CG, et al. Association between intensification of metformin treatment with insulin vs sulfonylureas and cardiovascular events and allcause mortality among patients with diabetes. Jama 2014; 311: 2288-96.

19. Herman ME, O'Keefe JH, Bell DSH, Schwartz SS. Insulin Therapy Increases Cardiovascular Risk in Type 2 Diabetes. Prog Cardiovasc Dis. 2017; 60:422-434.

20. Muniyappa R, Iantorno M, Quon MJ. An integrated view of insulin resistance and endothelial dysfunction. Endocrinol Metab Clin North Am. 2008; 37:685-711

21. de Zeeuw D, Remuzzi G, Parving HH et al. Proteinuria, a target for renoprotection in patients with type 2 diabetic nephropathy: lessons from RENAAL. Kidney Int 2004; 65: 2309-2320.

22. de Zeeuw D, Remuzzi G, Parving HH, Keane WF, Zhang Z, Shahinfar S, et al. Albuminuria, a therapeutic target for cardiovascular protection in type 2 diabetic patients with nephropathy. Circulation. 2004 Aug 24;110(8):921-7.

23. Microalbuminuria: target for renoprotective therapy PRO Sara S. Roscioni1,2, Hiddo J. Lambers Heerspink1,2 and Dick de Zeeuw Kidney International 2014; 86:40-49; doi:10.1038/ki.2013.490

24. Blak BT, Thompson M, Dattani H, Bourke A. Generalisability of The Health Improvement Network (THIN) database: demographics, chronic disease prevalence and mortality rates. Informatics in Primary Care 2011; 19(4): 251-5 
25. Anyanwagu U, Mamza J, Mehta R, Donnelly R, Idris I. Cardiovascular events and allcause mortality with insulin versus glucagon-like peptide-1 analogue in type 2 diabetes. Heart 2016; 102(19): 1581-1587.

26. Anyanwagu U, Mamza J, Donnelly R, Idris I. Effect of adding GLP-1RA on mortality, cardiovascular events and metabolic outcomes among insulin-treated patients with Type 2 Diabetes: A Large Retrospective UK Cohort Study. American Heart Journal. 2018; 196: 18-26.

27. El Nahas AM, Masters-Thomas A, Brady SA et al. Selective effect of low protein diets in chronic renal diseases. Br Med J (Clin Res). 1984; 289:1337-1341.

28. Laverman GD, de Zeeuw D, Navis G. Between-patient differences in the renal response to renin-angiotensin system intervention: clue to optimising renoprotective therapy? J Renin Angiotensin Aldosterone Syst. 2002;3:205-213.

29. Hellemons ME, Persson F, Bakker SJL, et al. Initial angiotensin receptor blockadeinduced decrease in albuminuria is associated with long-term renal outcome in type 2 diabetic patients with microalbuminuria: a post hoc analysis of the IRMA-2 trial. Diabetes Care. 2011; 34:2078-2083.

30. Apperloo $\mathrm{EM}^{1}$, Pena $\mathrm{MJ}^{1}$, de Zeeuw $\mathrm{D}^{1}$, Denig $\mathrm{P}^{1}$, Heerspink $\mathrm{HJL}^{1}$. Individual variability in response to renin angiotensin aldosterone system inhibition predicts cardiovascular outcome in patients with type 2 diabetes: A primary care cohort study Diabetes Obes Metab. 2018; 20:1377-1383

31. Deckert T, Feldt-Rasmussen B, Borch-Johnsen K, Jensen T, Kofoed-Enevoldsen A. Albuminuria reflects widespread vascular damage. The Steno hypothesis. Diabetologia. 1989;32:219-226.

32. Pedrinelli R, Giampietro O, Carmassi F, et al. Microalbuminuria and endothelial dysfunction in essential hypertension. Lancet. 1994;344:14-18.

33. Yilmaz MI, Sonmez A, Saglam M, et al. ADMA levels correlate with proteinuria, secondary amyloidosis, and endothelial dysfunction. J Am Soc Nephrol. 2008;19:388395 
34. Stehouwer CD, Gall MA, Twisk JW, Knudsen E, Emeis JJ, Parving HH. Increased urinary albumin excretion, endothelial dysfunction, and chronic low-grade inflammation in type 2 diabetes: progressive, interrelated, and independently associated with risk of death. Diabetes. 2002;51:1157-1165

35. Mykkänen L, Zaccaro DJ, Wagenknecht LE, Robbins DC, Gabriel M, Haffner SM. Microalbuminuria is associated with insulin resistance in nondiabetic subjects: the insulin resistance atherosclerosis study. Diabetes. 1998;47:793-800

36. Rabelink TJ, de Zeeuw D. The glycocalyyx-linking albuminuiria with renal and cardiovascular disease. Nat Rev Nephrol. 2015;11(11):667-76.

\section{Legend}

Table 1 - Baseline Characteristics of Study Participants

Table 2: Comparison of number of events, Event rate and Hazard Ratio of the Primary Outcomes between the treatment groups.

Table 3: Comparison of number of events, Event rate and Hazard Ratio of the Secondary Outcomes between the treatment groups.

Figure 1 - Kaplan-Meier survival analysis plot for All-cause Mortality between the two treatment groups (log-rank test p value $<0.001)$

Figure 2 - Kaplan-Meier survival analysis plot for Cardiovascular Events between the treatment groups $(\log$-rank test $\mathrm{p}$ value $=0.007)$ 
Figure 3 - Kaplan-Meier survival analysis plot for (A) 3-point Composite Endpoint (log-rank test $\mathrm{p}$ value $=0.006$ ). (B) Non-fatal Acute Myocardial Infarction (log-rank test $\mathrm{p}$-value $=0.086) .(\mathrm{C})$ Non-Fatal Stroke $(\log -$ rank test $\mathrm{p}$ value $=0.03)$. 
Table 1: Baseline Characteristics

\begin{tabular}{|c|c|c|c|c|}
\hline \multirow[b]{2}{*}{ Baseline Variables } & \multicolumn{4}{|c|}{ Post One-year ACR Categories } \\
\hline & $\begin{array}{l}\geq 300 \mathrm{mg} / \mathrm{g} \\
(\mathrm{n}=9,522)\end{array}$ & $\begin{array}{c}<300 \mathrm{mg} \\
(\mathrm{n}=1,552)\end{array}$ & $\begin{array}{c}\text { Total } \\
(\mathrm{n}=\mathbf{1 1 , 0 7 4}) \\
\end{array}$ & p-value \\
\hline \multicolumn{5}{|l|}{ Demographics } \\
\hline Age (yrs), Mean (SD) & $62.8(13.5)$ & $59.8(13.5)$ & $62.3(13.6)$ & $<0.001$ \\
\hline \multicolumn{5}{|l|}{ Gender, No. (\%) } \\
\hline Male & $5070(53)$ & $829(53)$ & $5899(53)$ & 0.901 \\
\hline \multicolumn{5}{|l|}{ Townsend deprivation, No. (\%) } \\
\hline Least deprived & $1809(20)$ & $318(21)$ & 2127 (19) & \\
\hline 2nd quintile & $1835(20)$ & $301(20)$ & $2136(19)$ & \\
\hline 3rd quintile & $1948(21)$ & $310(21)$ & $2258(20)$ & 0.734 \\
\hline 4th quintile & $1980(22)$ & $313(21)$ & $2293(21)$ & \\
\hline Most deprived & $1504(17)$ & $241(16)$ & $1745(16)$ & \\
\hline \multicolumn{5}{|l|}{ Clinical Parameters, Mean (SD) } \\
\hline $\operatorname{HbA1c}(\%)$ & $8.8(1.8)$ & $8.7(1.8)$ & $8.7(1.8)$ & \\
\hline$[\mathrm{mmol} / \mathrm{mol}]$ & $73(20)$ & $72(20)$ & $72(20)$ & 0.417 \\
\hline $\mathrm{ACR}(\mathrm{mg} / \mathrm{g})$ & $118.1(62.8)$ & $58.8(24.1)$ & $110.7(62.5)$ & $<0.001$ \\
\hline $\operatorname{BMI}\left(\mathrm{kg} / \mathrm{m}^{2}\right)$ & $32.7(6.8)$ & $31.9(6.8)$ & $32.6(6.8)$ & $<0.001$ \\
\hline Diabetes duration (yrs) & $4.5(4.8)$ & $4.0(4.7)$ & $4.4(4.8)$ & $<0.001$ \\
\hline Duration on insulin (yrs) & $4.0(6.4)$ & $3.6(6.1)$ & $4.0(6.4)$ & 0.004 \\
\hline Weight $(\mathrm{Kg})$ & $91.7(18.8)$ & $91.0(18.9)$ & $91.6(18.8)$ & 0.131 \\
\hline Height (m) & $1.7(0.1)$ & $1.7(0.1)$ & $1.7(0.1)$ & 0.104 \\
\hline $\mathrm{SBP}(\mathrm{mmHg})$ & $138.4(23.3)$ & $132.9(22.8)$ & $137.6(23.3)$ & $<0.001$ \\
\hline $\mathrm{DBP}(\mathrm{mmHg})$ & $75.7(10.9)$ & $75.0(10.6)$ & $75.6(10.9)$ & 0.008 \\
\hline $\mathrm{eGFR}\left(\mathrm{mls} / \mathrm{min} / 1.73 \mathrm{~m}^{2}\right)$ & $59.0(21.2)$ & $65.6(20.4)$ & $59.9(21.2)$ & $<0.001$ \\
\hline $\mathrm{TC}(\mathrm{mmol} / \mathrm{l})$ & $4.6(1.3)$ & $4.6(1.2)$ & $4.6(1.3)$ & 0.715 \\
\hline HDL (mmol/l) & $1.2(0.4)$ & $1.2(0.4)$ & $1.2(0.4)$ & 0.364 \\
\hline $\mathrm{LDL}(\mathrm{mmol} / \mathrm{l})$ & $2.4(1.1)$ & $2.4(1.1)$ & $2.4(1.1)$ & 0.574 \\
\hline Triglyceride (mmol/L) & $2.2(1.2)$ & $2.0(1.2)$ & $2.1(1.2)$ & $<0.001$ \\
\hline Albumin $(\mathrm{g} / \mathrm{L})$ & $4.0(0.4)$ & $4.1(0.4)$ & $4.0(0.4)$ & $<0.001$ \\
\hline \multicolumn{5}{|l|}{ Smoking status, No. (\%) } \\
\hline Non-smoker & 4633 (49) & $740(48)$ & $5373(49)$ & \\
\hline Ex-smoker & $3551(37)$ & $568(37)$ & $4119(37)$ & 0.219 \\
\hline Current smoker & $1338(14)$ & $244(16)$ & $1582(14)$ & \\
\hline \multicolumn{5}{|l|}{ Alcohol status, No. (\%) } \\
\hline Non-drinker & $3194(34)$ & $487(31)$ & $3681(33)$ & \\
\hline Ex-drinker & $1091(11)$ & $180(12)$ & $1271(11)$ & 0.235 \\
\hline Current drinker & $5237(55)$ & $885(57)$ & $6122(55)$ & \\
\hline \multicolumn{5}{|l|}{ BMI Categories, No. (\%) } \\
\hline Normal & $1223(13)$ & $235(15)$ & $1458(13)$ & \\
\hline Overweight & $2231(23)$ & $399(26)$ & $2630(24)$ & 0.002 \\
\hline Obese & $6068(64)$ & $918(59)$ & $6986(63)$ & \\
\hline \multicolumn{5}{|l|}{ GLTs, No. (\%) } \\
\hline Metformin & $8163(86)$ & $1312(85)$ & $9475(86)$ & 0.216 \\
\hline Sulphonylurea & $7316(77)$ & $1152(74)$ & $8468(76)$ & 0.025 \\
\hline Thiazolidinedione & $3005(32)$ & $494(32)$ & $3499(32)$ & 0.831 \\
\hline GLP-1RA & $1007(11)$ & $179(12)$ & $1186(11)$ & 0.258 \\
\hline SGLT2i & $40(0)$ & $10(1)$ & $50(0.5)$ & 0.222 \\
\hline Glinides & $428(4)$ & $72(5)$ & $500(5)$ & 0.800 \\
\hline DPP4i & $1353(14)$ & $222(14)$ & $1575(14)$ & 0.921 \\
\hline \multicolumn{5}{|l|}{ Use of Medications, No. (\%) } \\
\hline Aspirin & 9213 (99) & $1478(99)$ & $10691(99)$ & 0.138 \\
\hline
\end{tabular}


Antihypertensive

$8493(92)$

$1316(89)$

$9809(92)$

$<0.001$

- ACE inhibitors

$7505(81)$

$1154(78)$

$8659(81)$

0.002

- ARBs

2957 (32)

$409(28)$

$3366(31)$

0.001

- Calcium channel blockers

$5302(56)$

$754(51)$

$6056(57)$

$<0.001$

- Beta-blockers

- Diuretics

4807 (52)

$699(47)$

$5506(51)$

$<0.001$

LLTs

$9214(96)$

$1479(95)$

$10693(94)$

0.001

Comorbidities, No. $(\%)^{\mathrm{c}}$

CHD

8407 (91)

1347 (91)

9754 (91)

0.834

$2992(31) \quad 404(26) \quad 3396(31) \quad<0.001$

$1365(14) \quad 185(12) \quad 1550(14) \quad 0.011$

PAD

$1433(15)$

0.011

Hypoglycaemia

1711 (18)

267 (17)

0.465

\footnotetext{
Abbreviations:

GLP-1RA (Glucagon-like peptide-1 receptor agonist); SGLT2i (Sodium-glucose Cotransporter-2 (SGLT2) Inhibitors); DPP4i (Dipeptidyl-peptidase 4 inhibitors); GLTs (Glucose Lowering Therapies); BMI (body mass index); SBP (systolic blood pressure); DBP (diastolic blood pressure); HbAlc (hemoglobin Alc); HDL (highdensity lipoprotein); LDL (low-density lipoprotein); TC (total cholesterol); eGFR (estimated glomerular filtration rate); LLTS (lipid lowering therapies); PAD (peripheral arterial disease); CHD (coronary heart disease); ACR (albumin creatinine ratio); ACEi (Angiotensin Converting Enzyme Inhibitors); ARBs (Angiotensin II Receptor Blockers); SD (standard deviation)
} 
Table 2: Comparison of number of events, Event rate and Hazard Ratio of the Primary Outcomes between the treatment groups.

\begin{tabular}{|c|c|c|c|}
\hline \multirow[b]{2}{*}{ Primary End Points } & \multicolumn{3}{|c|}{ Post One-year ACR } \\
\hline & $\begin{array}{l}\geq 300 \mathrm{mg} / \mathrm{g} \\
(\mathrm{n}=9522)\end{array}$ & $\begin{array}{c}<300 \mathrm{mg} \\
(\mathrm{n}=1552) \\
\end{array}$ & p-value \\
\hline $\begin{array}{l}\text { All-Cause Mortality } \\
\text { Number of deaths } \\
\text { Death rates }(95 \% \mathrm{CI}) \\
\text { HR }(95 \% \mathrm{CI}) \\
\text { aHR }^{\mathrm{a}}(95 \% \mathrm{CI})\end{array}$ & $\begin{array}{c}621 \\
16.7(15.5-18.1) \\
1 \text { (reference) } \\
\mathbf{1} \text { (reference) }\end{array}$ & $\begin{array}{c}61 \\
9.7(7.6-12.5) \\
0.57(0.44-0.75) \\
\mathbf{0 . 6 9}(\mathbf{0 . 5 2}-\mathbf{0 . 9 1})\end{array}$ & $\begin{array}{c}<0.001 \\
\mathbf{0 . 0 0 8}\end{array}$ \\
\hline $\begin{array}{l}\text { Cardiovascular Events } \\
\text { Number of events } \\
\text { Event rates }(95 \% \mathrm{CI}) \\
\text { HR }(95 \% \mathrm{CI}) \\
\text { aHR }(95 \% \mathrm{CI})\end{array}$ & $\begin{array}{c}438 \\
13.4(12.2-14.7) \\
1 \text { (reference) } \\
\mathbf{1} \text { (reference) }\end{array}$ & $\begin{array}{c}50 \\
9.0(6.8-11.8) \\
0.67(0.50-0.90) \\
\mathbf{0 . 7 3}(\mathbf{0 . 5 4}-\mathbf{0 . 9 8})\end{array}$ & $\begin{array}{l}0.007 \\
\mathbf{0 . 0 4 1}\end{array}$ \\
\hline \multicolumn{4}{|c|}{$\begin{array}{l}\text { Abbreviations: HR, hazard ratio; aHR, Adjusted Hazard Ration; ACR, albumin to creatinine ratio. } \\
{ }^{a} \text { Hazard ratio in both all-cause mortality and CV events was adjusted for age, BMI, duration of diabetes, } \\
\text { gender, Socio-economic status, change in HbAlc, Systolic and Diastolic BP, Change in Mean Arterial } \\
\text { Pressure (MAP), Lipid profile, Use of antihypertensive medications and comorbidities as Heart failure, } \\
\text { CHD and PAD. } \\
{ }^{b} \text { Cardiovascular Events - Composite of non-fatal Myocardial Infarction and Stroke }\end{array}$} \\
\hline
\end{tabular}

Table 3: Comparison of number of events, Event rate and Hazard Ratio of the Secondary Outcomes between the treatment groups.

\begin{tabular}{|c|c|c|c|}
\hline \multirow[b]{2}{*}{ Secondary End Points } & \multicolumn{3}{|c|}{ Post One-year ACR } \\
\hline & $\begin{array}{l}\geq 300 \mathrm{mg} / \mathrm{g} \\
(\mathrm{n}=9522)\end{array}$ & $\begin{array}{l}<300 \mathrm{mg} / \mathrm{g} \\
(\mathrm{n}=1552) \\
\end{array}$ & p-value \\
\hline \multicolumn{4}{|l|}{ Composite Outcome $^{\mathrm{a}}$} \\
\hline Number of events & 1062 & 111 & \\
\hline Event rates $^{\mathrm{b}}(95 \% \mathrm{CI})$ & $32.5(30.6-34.5)$ & $19.9(16.5-24.0)$ & \\
\hline HR $(95 \% \mathrm{CI})$ & 1 (reference) & $0.61(0.50-0.74)$ & $<0.001$ \\
\hline $\mathrm{aHR}^{\mathrm{c}}(95 \% \mathrm{CI})$ & 1 (reference) & $0.73(0.59-0.89)$ & 0.002 \\
\hline \multicolumn{4}{|l|}{ Non-fatal Myocardial Infarction } \\
\hline Number of events & 64 & 5 & \\
\hline Event rates $(95 \% \mathrm{CI})$ & $1.8(1.4-2.3)$ & $0.8(0.3-2.0)$ & \\
\hline $\mathrm{HR}(95 \% \mathrm{CI})$ & 1 (reference) & $0.46(0.18-1.14)$ & 0.094 \\
\hline aHR $(95 \% \mathrm{CI})$ & 1 (reference) & $0.66(0.26-1.70)$ & 0.387 \\
\hline \multicolumn{4}{|l|}{ Non-fatal Stroke } \\
\hline Number of events & 374 & 45 & \\
\hline Event rates $(95 \% \mathrm{CI})$ & $11.1(10.0-12.3)$ & $7.9(5.9-10.6)$ & \\
\hline $\operatorname{HR}(95 \% \mathrm{CI})$ & 1 (reference) & $0.71(0.52-0.97)$ & 0.030 \\
\hline aHR $(95 \% \mathrm{CI})$ & 1 (reference) & $0.72(0.52-0.97)$ & 0.032 \\
\hline
\end{tabular}


${ }^{c}$ Hazard ratio in all the secondary endpoints was adjusted for age, BMI, duration of diabetes, gender, Socio-economic status, change in HbAlc, Systolic and Diastolic BP, Change in Mean Arterial Pressure $(M A P)$, Lipid profile, Use of antihypertensive medications and comorbidities as Heart failure, CHD and $P A D$. 


\section{Unadjusted Kaplan-Meier estimates for All-cause Mortality}

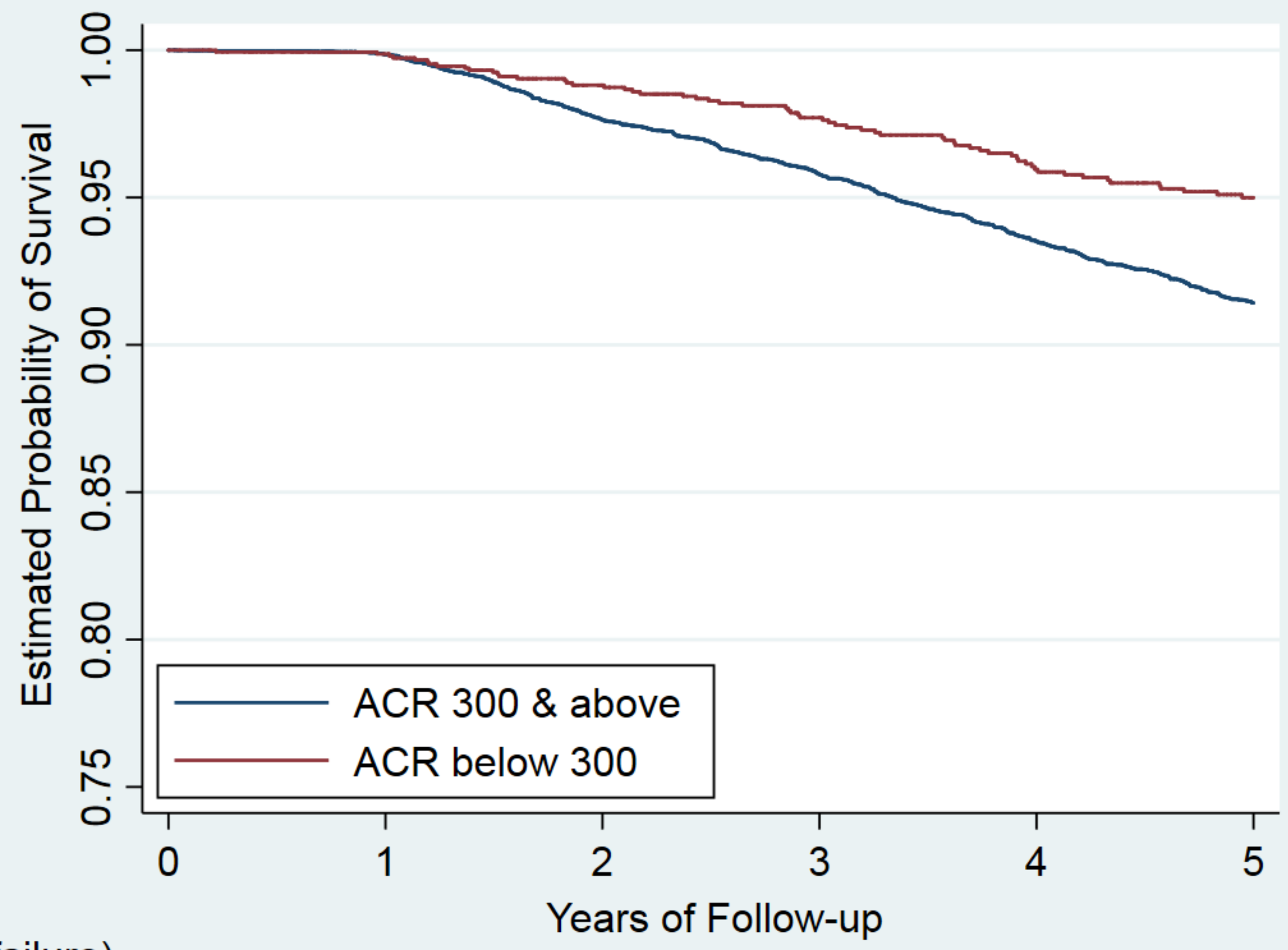

No at risk (failure)

ACR 300 \& above 9522 (14) 9032 (187) 7827 (140) 6880 (153) 5983 (127) 5171 ACR below 3001552 (2) 1484 (15) 1322 (14) 1180 (20) 1052 (10) 925 
Unadjusted Kaplan-Meier estimates for Cardiovascular Events

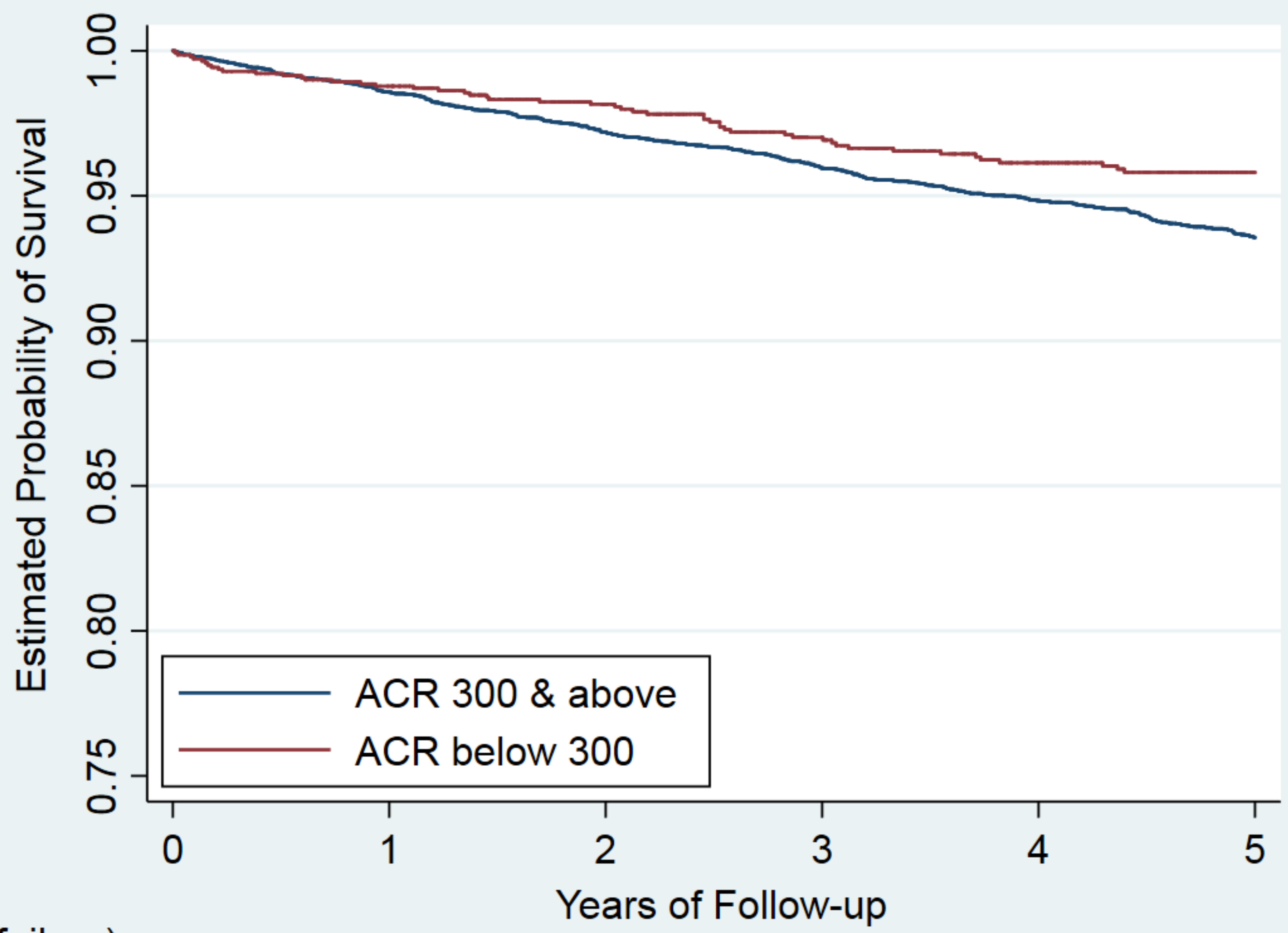

No at risk (failure)

ACR 300 \& above 8564 (120) 8012 (105) 6899 (82) 6020 (66) 5205 (65) 4493 ACR below 3001409 (17) $1331 \quad$ (8) 1177 (13) 1039 (9) 921 
